\title{
Assessment Of Knowledge, Attitude And Practice Of Mothers On The Effects Of Sunlight Exposure And Its Associated Factors Among Infants Found In Debre Tabor Town, North Central Ethiopia, 2018
}

Dejen Getaneh Feleke ( $\nabla$ dejengetaneh38@gmail.com )

Debre Tabor University

Endalkachew Mesfin

Debre Tabor Health science college

Gashew Mekete

Debre Tabor Health science College

Research

Keywords: Sunlight Exposure, Debre Tabor Town, Ethiopia

Posted Date: September 28th, 2020

DOI: https://doi.org/10.21203/rs.3.rs-80007/v1

License: (c) (1) This work is licensed under a Creative Commons Attribution 4.0 International License.

Read Full License 
Assessment Of Knowledge, Attitude And Practice Of Mothers On The Effects Of Sunlight Exposure And Its Associated Factors Among Infants Found Debre Tabor Town, , North Central Ethiopia, 2018 .

Dejen Getaneh ${ }^{1} * \quad$ (dejengetaneh38@gmail.com), Endalkachew Mesfin ${ }^{2}$ (endmes909@gmail.com), Gashew Mekete ${ }^{3}$ (mulunehmekete@gmail.com)

Authors' affiliation:

${ }^{1}$ Department of Nursing, College of Health Sciences, Debre Tabor University, P.O.BOX 272, Debre Tabor, Ethiopia.

${ }^{2}$ Departments of Public Health, Debre Tabor Health Science College, Debre Tabor, Ethiopia.

${ }^{3}$ Department of Nursing, Debre Tabor Health Science College, Debre Tabor, Ethiopia.

*Corresponding author: Lecturer of Pediatrics and Child Health Nursing @ Debre Tabor University, email: dejengetaneh38@gmail.com: P.O.Box:272, Debre Tabor University Debre Tabor, Ethiopia. 


\section{Abstract}

Background: Early morning sunlight exposure for infants was a good practice to prevent rickets and alleviate the problem of vitamin D efficiency. Rickets is a major public health problem in many countries of the world. In many rich industrialized countries, the prevalence of rickets in the general population diminished after the introduction of dietary supplementation. But the most cost-effective way of getting vitamin D is simply from sunlight exposure rather than vitamin-D supplementation and advanced treatment. The main objective of this study is to assess the knowledge, attitude and practice of mothers on the effects of sunlight exposure and its associated factors among infants found in Debre Tabor town, North central Ethiopia, 2018.

Methods: community-based cross-sectional study had been conducted among 105 mothers with infants in Debre Tabor city, South Gondar Zone, Amhara, Northcentral Ethiopia, 2018 from October 30 -/2018-January 1/2019. To select study participants simple random sampling techniques was employed. Data was entered into Epi info version 7.2.0.1, and exported to SPSS window version 20 for analysis. Binary and Multivariable logistic regression was used to see the association between dependent and independent variables. Odds ratio with $95 \%$ confidence interval was computed. P-value $\leq 0.05$ was used to declare association.

Results: The overall knowledge, practice and attitude of the mothers about sunlight exposure were $61.14 \%, 59.44 \%$, and $61 \%$ respectively, regarding factors associated with knowledge, practice and attitude of mothers about sunlight exposure were highly influenced by good time exposure for sunlight exposure, mother who exposed their infants to sunlight exposure sometimes were 3.2 times less for acquiring knowledge than mothers who expose their infants who warm daily [AOR: *3.2(1.02-6.4)], mothers who had an occupation of daily laborer were 3.4 times less likely to practice sunlight exposure to their infants governmental workers [AOR: *3.4(0.8 2.8)] and. mothers who do not believe about the good effect of sunlight exposure had 3.3 times negative attitude towards about sunlight exposure than who thinks well [AOR; **3.3(1.5-8.9)] were significantly associated with knowledge, practice and attitude of mothers about sunlight exposure and the total attitude of the mother's sunlight exposure was lower than knowledge and practice .Hence; Based on the result the concerned body and health care providers should create awareness about the effect of sunlight exposure through health education.

Keywords: Sunlight Exposure, Debre Tabor Town, Ethiopia 


\section{Plain English summary}

Rickets is a major public health problem in many countries of the world. In many rich industrialized countries, the prevalence of rickets in the general population diminished after the introduction of dietary supplementation. But the most cost-effective way of getting vitamin D is simply from sunlight exposure rather than vitamin-D supplementation and advanced treatment. The main objective of this study is to assess the knowledge, attitude and practice of mothers on the effects of sunlight exposure and its associated factors among infants found in Debre Tabor town, North central Ethiopia, 2018. From the total respondents of 105 mothers, the entire required sample was included and it produces the response rate of $100 \%$, despite $5 \%$ of retested samples. The overall knowledge, practice and attitude of the mothers about sunlight exposure were $61.14 \%, 59.44 \%$, and $61 \%$ respectively. mothers whose marital status of singles were 2.9 times more likely to report for inadequate knowledge about sunlight exposure than married mothers [AOR: **2.9(1.4-7.9)].Regarding good time exposure for sunlight exposure, the mother who exposed their infants to sunlight exposure sometimes were 3.2 times less for acquiring knowledge than mothers who expose their infants who warm daily [AOR: *3.2(1.02-6.4)]. In conclusion; generally mother's knowledge, practice and attitude were lower when compared with different kinds of literature. So Based on the result the concerned body and health care providers should create awareness about the effect of sunlight exposure through health education.

\section{BACKGROUND}

Different kinds of literature sunshine was introduced in 1958 and sunlight was first used for neonatal jaundice, placing a child in a room where sunlight enters through window panes (not in direct sunlight) for 10 minutes twice a day was often used to help treat mild neonatal jaundice and even sunlight exposure of the mother during pregnancy can prevent rickets and multiple sclerosis among newborn and infant (1). Rickets and retinopathy of the newborn and infants indirectly linked with ineffective sunlight exposure and rickets are common in children in SubSaharan Africa, including (2). While short exposure to solar ultraviolet radiation (UVR) can elicit increased skin pigmentation, a protective response mediated by epidermal melanocyte, chronic exposure can lead to skin cancer and photoaging, however, the molecular mechanisms that allow human skin to detect and respond to UVR remain incompletely understood (3). Vitamin D, which is primarily obtained through exposure to sunlight (specifically ultraviolet 
radiation B (UVR-B)), has been inversely associated with several complex diseases but despite the advantages of sunlight exposure in optimal amount, greater sunlight exposure causes skin cancer $(3,4)$. The potential of UVR to be beneficial for some health outcomes but detrimental for others has prompted a public health debate on how to balance the positive and negative consequences of sun exposure (4). There are few modifiable risk factors for Hodgkin lymphoma (HL), the most common cancer among young adults in Western populations. Some studies have found reduced risk with exposure to ultraviolet radiation (UVR), but findings have been inconsistent and limited to HL as a group or the most common subtypes (5). Infants' risk of rickets occurs due to insufficient sunlight exposure and lack of exposure to sunshine was the single most important cause of rickets in Ethiopian children. Some pioneering studies, as well as more recent work, suggested that daily exposure to sunshine remains the cheapest, safest and most effective method of preventing the disease. Generally, the scar that it late by rickets are very high and the main strategies to tackle this problem strong health education to change maternal behavior to expose infants to sunshine were adopted as the main strategy to combat rickets (6). Rickets is widely prevalent in many tropical and subtropical regions despite abundant sunshine. WHO now estimates that globally one billion people have VDD and the incidence of rickets is particularly high in children who live in crowded houses almost devoid of sunlight exposure due to poor awareness and practice of mothers about the advantages of sunlight exposure (1). Different studies showed that insufficient maternal circulating concentration of 25hydroxyvitamin D [25(OH) D] during pregnancy, also another contributing factors for the efficiency of vitamin D, in addition to poor utilization of sunlight exposure (2).besides the advantages of sunlight exposure, inappropriate and misuse of sunlight exposure in recent years, exposure to sunlight has been a subject of epidemiological interest both due to its beneficial as well as adverse effects on human health $(1,2)$. It is an important etiological factor in the development of skin cancers and sun-related eye problems when exposure is high (3). However, the exposure to solar ultraviolet radiation (UVR) is an essential step for the production of Vitamin D, and also the main source of vitamin D in the human body (4). Studies worldwide identify a lack of sun exposure as the main cause of rickets and it is a major public health problem in many countries of the world. In many rich industrialized countries, the prevalence of rickets in the general population diminished after the introduction of dietary supplementation (6). However, in such countries, vitamin-D deficiency rickets has re-emerged in recent years, 
particularly among groups with limited exposure to UVB containing sunshine. Infants at risk of rickets are those whose mothers had poor vitamin D status during pregnancy and those exclusively breastfed for a prolonged period with little skin exposure to UVB (7).

The purpose of this study would be intended primarily to assess mothers' KAP and factors affecting their practice about sunlight exposure of their infants. Therefore, this is very important to identify areas for improvement regarding sunlight exposure and to improve the health of the community. In addition to this, in our country, Ethiopia researches regarding sunlight exposure are scarce particularly in this study area. Therefore the research study may provide baseline information. So, this finding used as one input to reduce child mortality and morbidity related to rickets and the sustainable development goal would be achieved through adequate KAP of

mothers about sunlight exposure. For researchers, it would be used as a reference for any high scale related study. For institutions, the research output can be used to improve infant and child health by creating awareness about the importance of sunlight exposure for parents. Since most children are at risk for rickets, and mothers had limited KAP on the effect of sunlight exposure coupled with limited research conducted on the title particularly around the study area, the research will employ primarily to assess mothers' KAP affecting their knowledge about sunlight exposure of their infants will be conducted in Debre Tabor Town. (Figure1 Conceptual framework)

\section{Methods}

\section{Study Area and study period}

This study was conducted at Debre-Tabor town. Which is far from $103 \mathrm{~km}$ from the capital city of Amhara National Regional State It is found $666 \mathrm{~km}$ away from Addis Ababa. The Town divides with 6 kebeles and has Weyina Dega. Based on the 2018 Census conducted by the local Statistical Agency of Ethiopia (LSA), town has a total population of 60,563 , whom $31.863(52.6 \%)$ are females and 28,700(47.4\%) are males, $8200<5$ children, 1886 of $<1$ year old and 2041 were pregnant mothers who found in this town . Based on the facility-based report of 2010 the Ethiopian Physical year 1268 children were delivered in Debre Tabor hospital with the death of from the total admission of 1513. Based on the 3 health center report 960 babies were delivered in the town. There are one hospital and three health centers in Debre-tabor town offering health care services for the total population and Debre Tabor (." Mount Tabor") is a 
town and a Woreda in north-central Ethiopia. Located in the Debub Gondar Zone of the Amhara Region of Ethiopia, about 100 kilometers southeast of Gondar and 50 kilometers east of Lake Tana, this historic town has a latitude and longitude of $11^{\circ} 51^{\prime} \mathrm{N} 38^{\circ} 1^{\prime} \mathrm{E}$ with an elevation of 2,706 meters $(8,878 \mathrm{ft})$ above sea level. The presence of at least 48 springs in the area contributed to the development of Debre Tabor and it has the climatic condition of Dega to Weyina Dega, it also found between $19^{\circ} \mathrm{c}$ to $25^{\circ} \mathrm{c}$ climatic condition. The study was conducted from October 30 -/2018-January 1/2019

\section{Study design and participants characteristics}

A community-based cross-sectional study had been conducted. The source populations were all mothers having children < 1year old found in Debre Tabor Town; South Gondar was the source population for this study. The study population would be mothers with infants found in Debre Tabor Town at the time of data collection and who fulfill the inclusion criteria. Each mother of having < 1years old infants found in Debre Tabor Town during the study period. Mothers with <

year old infant with mentally and physically capable of being responded and who are volunteer to participate in the study was be included in the study part. Mothers with infants who are seriously ill, mentally incompetent, and unable to communicate and who are not voluntary to participate in the study were excluded from the study.

Simple size determination and sampling procedure

In this study, the sample size was determined by using a single population proportion formula (15). $\mathrm{n}=\underline{(\mathrm{Z} \alpha / 2) 2 * \mathrm{P}(1-\mathrm{p})}$

$\mathrm{d} 2$

$\mathrm{n}=\underline{(1.96) 2(0.93)(1-0.93)}$

$(0.05) 2$

$\mathrm{n}=100$

Since the population is less than 10,000 , the reduction formula was used.

$$
\text { So, } \mathrm{n}=\frac{\mathrm{n}_{0}}{1+\frac{\left(\mathrm{n}_{0}-1\right)}{\mathrm{N}}}
$$

So, $\mathrm{n}=\frac{100}{1+\frac{(100-1)}{1886}}=95$

By adding $10 \%$ none response rate the total sample size was $95+9.5=105$, The total sample size was 105. Where: $n=$ the desired sample size, $P=$ practice of mothers on sunlight exposure on 
similar studies during the assessment was $93 \%,(15) . Z \alpha / 2=$ standard normal variation value at a confidence interval of $95 \%$ (1.96), $\mathrm{d}=$ the margin error between the sample and the population. Simple random sampling technique was employed to select the study participants. (Figure 1: Schematic presentation of the sampling procedure of the Study)

\section{Variables of the Study}

\section{Independent variables}

Socio-demographic factors (age, religion, ethnicity, marital status, educational status, occupation, family size), source of information (physician, nurse/midwife, TV/Radio, neighbors/elder people), time of sunlight exposure (morning, afternoon, evening), opinion about sunlight exposure (good, bad), the belief of mothers on sunlight exposure (good, bad), place of exposure (indoor, outdoor).

\section{Dependent variables}

Knowledge, Attitude and practice of sunlight exposure

\section{Operational definition}

Knowledge - The theoretical understanding of mothers' about sunlight exposure of infants. Practice - Mothers' activity or behavioral experience in relation to sunlight exposure of infants. 
Good knowledge -Those mothers that were responded to knowledge questions and scored above the mean

Poor knowledge - Those mothers that were responded to knowledge questions and scored 4 and below the mean

Good practice- Those mothers that were responded to practice questions and scored above the mean

Poor practice- Those mothers that were responded to practice questions and scored 6 and below the mean

Good attitude - Those mothers that were responded to practice questions and scored above the mean

Poor attitude - Those mothers that were responded to practice questions and scored 6 and below the mean

\section{Data collection procedure and instrument}

Data was collected through face to face interview method after preparing a structured pre-tested questionnaire, prepared via reviewing of literature and had been used. The questionnaire initially prepared in English and translated into Amharic (local language) and again retranslated back to English to check for any inconsistencies or distortions in the meaning of words and concepts. Three data collectors (two BSc-nurses and two diploma midwifery) and one supervisor and data were collected by face to face interview techniques. That would not work in that unit were being recruited as data collectors, one BSc nurse was recruited as a supervisor. All data collectors and supervisors were trained for two days on their responsibilities for describing the purpose of the study, how to collect the data and telling clients the importance of honest and genuine reply on responding to questions. Mothers were interviewed after they got the services. The principal investigator and the supervisor would strictly follow the overall activities of the data collection on a daily base to ensure the completeness of the questionnaire and to give further clarification. To select participants' simple ransom or lottery sampling method was used.

\section{Data processing and analysis}

After checking the completeness of the data, it was entered into Epi info version 7.2.0.1, and then; it was exported to SPSS Version 20 for analysis. Descriptive analysis was done by 
computing proportions and summary statistics. The association between each independent variable and the outcome variable was assessed by using binary logistic regression. All variables with $\mathrm{P} \leq 0.2$ in the bivariate analysis were included in the final model of multivariable analysis in order to control all possible confounders.

Adjusted odds ratio along with 95\% CI were computed and P-value $\leq 0.05$ was considered to declare factors that have statistically significant association with Sunlight Exposure by using multivariable analysis in the binary logistic regression. The goodness of fit was tested by Hosmer-Lemeshow statistic test. Finally; the result is presented in the form of texts, tables and graphs.

\section{Data quality assurance}

The quality of data was ensured by doing the questioner was pre-tested on $5 \%$ of the total sample size at Nefas Mewucha town that is assumed to have Similar Characteristics of the targeted population. Based on their feedback the necessary amendment had been done and the questioner was assessed for its clarity; the completeness and evaluate the validity and content of the questionnaire and modified accordingly close supervision had been made during the data collection and appropriate feedback was provided. Was provided to the data collectors for one day by the principal investigator the Training was focused on the objective, how to obtain consent, keeping confidentiality of the information they gathered. The collected data was

cheeked for its completeness every day before the following day of data collection by supervisors and the principal investigator and Corrective measures had been taken according to the finding during supervision.

\section{Ethical consideration}

Ethical clearance was obtained from Research Ethics Committee of Debre Tabor university department of Nursing. Then, the participants of the study were informed about the purpose of the study, the importance of their participation, and their right to withdraw at any time. Verbal informed consent was obtained prior to data collection, written informed consent was obtained from a parent or guardian for participants under 16 years old. Then data collects from volunteer mothers. Mothers who are not practice Sunlight Exposure during the data collection period were advised regarding to use of Sunlight Exposure. 


\section{Results}

\section{Socio-demographic characteristics of the respondents}

From the total respondents of 105 mothers, the entire required sample was included and it produces the response rate of $100 \%$, despite $5 \%$ of retested samples. The mean age and standard deviation of the baby were $0.58 \pm 0.3$ years respectively with the mean age and standard deviation of the mother $24.5 \pm 6.21$ years respectively. Regarding the religion of the respondents, $85.7 \%$ (90) of the respondents follow orthodox religion and $96.2 \%$ (101) of the respondents were Amhara in nations. Among the respondents of 105 mothers, $72.4 \%(76)$ of them were engaged with marriage and majority or $46.6 \%$ (49) respondents were governmental employees in their occupational status. Regarding the educational status of the respondents, $44.8 \%$ (47) of the mothers were diploma and above and $48.6 \%$ ( 51) of their husbands were also diploma and above in their educational status who are almost similar with their wives educational status. On the other hand75.2\%, (79) of the mothers had 1-3 children. (Table- 1)

\section{Knowledge of mothers about sunlight exposure}

The overall knowledge of mothers about the effect of sunlight exposure was $61.14 \%$ and $80 \%(84)$ of the mothers know the effect of sunlight exposure on their infants. Regarding sources 
information of mothers on the effect of sunlight exposure on infants, 45.2\%( 38) and 34.5\%( 29) of mothers got information about sunlight exposure from midwives/nurses and physicians respectively. On the other way, $74.3 \%(78)$ of mothers testify the benefits of sunlight exposure. Among mothers knows the benefit of sunlight of exposure, 32/78 or $41 \%$ (32) of mothers testify sunlight exposure as beneficial for strong bone and among 105 respondents $71.4 \%$ ( 75) of mothers said that sunlight is not harmful but $28.6 \%$ (30) of the respondents said that sunlight exposure to infants are harmful. Among mothers who respond on the harmful effect of sunlight exposure, $16 / 30$ or $53.4 \%$ (16) of the mothers said that sunlight exposure can cause sunlight exposure. Regarding a good time for exposure of infants for sunlight exposure, $71.4 \%$ ( 75) of mothers said that morning is a good time for exposure. (Table 2). (Figure 3)

\section{Practice of mothers on sunlight exposure of their infants}

The overall practice of mothers on the effect of sunlight exposure on their infants was $59.44 \%$. Regarding exposure of infants on sunlight exposure, 61.9\%(65) of mothers expose their infants on sunlight exposure. On this study, 41.55(27) of the infants were started sunlight exposure at the age of 16-30 days and 61.5\%(40) of mothers expose their infants to sunlight exposure daily and this one is the recommended frequency of sunlight exposure. The majority of mothers or 62/65 or $95.4 \%$ ( 62) of mothers exposure their infants for sunlight outdoor and $4.6 \%$ ( 3 ) of mothers only expose their infants to sunlight exposure indoor. On the other hand, 63/65 of mothers or 97 $\%$ (63) of mothers expose their infants on sunlight at Morning 8-10 AM and 46.1\%( 30) of the respondents expose their infants to sunlight exposure unclothed and $35.4 \%(23)$ of mothers expose their infants to sunlight exposure with completely covered their infants. The majority of the respondents or $43.1 \%$ (28) among 65 mothers warm their babies on sunlight 5-10 minutes and $69.2 \%$ (45) of them apply lubricant during warming infants on sunlight. Regarding mothers who apply lubricant or lotion during sunlight exposure $77.8 \%$ (35) out of 45 respondents were applying lotion before exposure of sunlight. Most mothers or about $53.3 \%$ (24) of mothers apply baby Vaseline. (Table 3). (Figure 4).

\section{Attitude of mothers about sunlight exposure}

From the total respondents, $61 \%$ of mothers had a positive attitude towards sunlight exposure and 39\% had a negative attitude towards sunlight exposure. Among the respondents of 105 mothers, $58.1 \%$ (61) and 61\% (64) of mothers had a positive and good attitude towards sunlight exposure respectively. Among mothers who had a positive attitude towards sunlight exposure, 60 
out of 61 or 98.45(60) of mothers believed that sunlight exposure to infants aid to prevent rickets in infants. On the other way, 61.9\%(65) of mothers believed that sunlight exposure had no bad effect on infants and $62.9 \%$ (66) of the respondents out of 105 mothers believed that sunlight and good effect on their infants. (Table 4). (Figure 5).

\section{Factors associated with knowledge of mothers about sunlight exposure}

The Bivariate and logistic regression multivariate model was used to determine the significant $t$ factors of knowledge of mothers about sunlight exposure by using SPSS version 20 through coding the interested outcome variables. As it shows in table 4.Regarding the selected sociodemographic and knowledge related factors variables, age of the mothers $<35$ years, marital status of the mother, educational level of the mothers, time of exposure to sunlight, occupation of the mother and religion of status of the respondents were showed that statically significant association with knowledge of the mother about sunlight exposure in Bivariate analysis, but occupational status and religion the mother of $t$ significance was disappeared in the final steps of multivariate analysis. Among the selected socio-demographic and knowledge related factors variables age of the mothers $<35$ years, marital status of the mother, educational level of the mothers \& time of exposure to sunlight showed that statically significant association with knowledge of mothers about sunlight exposure. age of the mothers < 35 years, 1.4 times had poor knowledge about sunlight exposure than the mothers' age of >35 years [AOR: *1.4(1.25.89]. On the other way studies mothers whose marital status of singles were 2.9 times more likely to report for inadequate knowledge about sunlight exposure than married mothers [AOR: **2.9(1.4-7.9)].Regarding good time exposure for sunlight exposure, the mother who exposed their infants to sunlight exposure sometimes were 3.2 times less for acquiring knowledge than mothers who expose their infants who warm daily [AOR: *3.2(1.02-6.4)]. (Table 5).

\section{Factors associated with the practice of mothers about sunlight exposure}

The Bivariate and logistic regression multivariate model was used to determine the significant $t$ factors of the practice of mothers about sunlight exposure by using SPSS version 20 through coding the interested outcome variables. As it shows in table 5. Regarding the selected sociodemographic and practice related variables marital status of the mother, educational level of mothers ,occupation of the mother ,frequency of exposure husbands educational status, and place of exposure of the respondents were showed that statically significant association with practice of the mother about sunlight exposure in Bivariate analysis, but age of the mother, 
religion status, family size and ethnicity of the were neither significant nor disappeared with the final stage of multivariate analysis. Among the selected socio-demographic and practice related factors variables marital status of the mother, educational level of mothers, occupation of the mother, frequency of exposure husbands educational status, and place of exposure of the respondents showed that statically significant association with knowledge of mothers about sunlight exposure. Marital status of divorced mothers 1.87 times less practicing sunlight exposure to their infants than the mothers who had engaged with marriage [AOR: *1.87(1.00768)].Similarly, mothers who had an occupation of daily laborer were 3.4 times less likely to practice sunlight exposure to their infant's governmental workers [AOR: *3.4(0.8 2.8)]. Regarding educational status, mothers whose educational status of unable to read and write were 1.7 times less to practice sunlight exposure than mothers who are diploma and above in their educational status [AOR: **1.7(0.66-5.26)]. The same to mothers educational status, those husbands who had an educational status of unable to read and write were 1.6 times less practicing sunlight exposure than mothers who had a husband of diploma and above in their educational status [AOR;1.64(0.9-3.4)]. Regarding the frequency of exposure of infants for sunlight, mothers who expose their infants sometimes were 2.24 times less practicing sunlight exposure than mother who exposes daily[AOR; *2.24(0.2-3.2)]. (Table 6)

\section{Factors associated with an attitude of mothers about sunlight exposure}

The Bivariate and logistic regression multivariate model was used to determine the significant $\mathrm{t}$ factors of the attitude of mothers about sunlight exposure by using SPSS version 20 through coding the interested outcome variables. As it shows in table 6. Regarding the selected sociodemographic and attitude related variables age of the mothers, educational status of the mother marital status of the mother, opinion of the mother about sunlight exposure, belief of the mother about bad and effect of sunlight exposure were showed that statically significant association with attitude of the mother about sunlight exposure in Bivariate analysis, but religion status, occupational status of the mother, family size and ethnicity of the mothers were neither significant nor disappeared with the final stage of multivariate analysis. Among the selected socio-demographic and attitude related variables age of the mothers, educational status of the mother marital status of the mother, opinion of the mother about sunlight exposure, a belief of the mother about bad and effect of sunlight exposure showed that statically significant association with an attitude of mothers about sunlight exposure. Age of the mothers $>35$ years - 
49 years was 1.96 times had a bad attitude for sunlight exposure than the age of mothers $<35$ years [AOR: *1.96(1.3 7.6)]. Regarding marital status, mothers who had a single marital status 1.43 times believing bad about sunlight exposure to their infants than the mothers who had engaged with marriage [AOR: *1.43(1.3-8.1)]. Similarly, mothers whose educational status of unable to read and write were tied with traditional believes 1.97 times about sunlight exposure to their infants than who had a diploma and above in their educational status [AOR: *1.97(1.008.6)]. Regarding the opinion of mothers whose opinion bad were 2.1 times believed bad than who had a good opinion about sunlight exposure [AOR: *2.1(0.1-2.84)]. Mothers who think about the bad effect of sunlight exposure were 1.3 times believed bad about sunlight exposure than who thinks good about sunlight exposure [AOR; *1.3(1.00-4.97)]. On the other way, mothers who do not believe about the good effect of sunlight exposure had 3.3 times negative attitude towards about sunlight exposure than who thinks well [AOR; **3.3(1.5-8.9)]. (Table 7)

\section{Discussion}

From this study the overall knowledge of mothers about the effect of sunlight exposure was $61.14 \%$ and $80 \%(84)$ of the mothers know the effect of sunlight exposure on their infants but a community based cross-sectional study conducted in England to assess the effect of maternal sunshine exposure on the infant revealed that $89.6 \%$ of the mothers knew about the good effect of sunlight exposure and the result in this study showed the level of knowledge mothers was lower than the study done in England and this difference may be due to information and technology use difference (1). In this study $41 \%(32)$ of mothers testify sunlight exposure as beneficial for strengthen bone and the same study conducted in Turkey on the effect of sunlight exposure and vitamin D deficiency on infant showed that $68.2 \%$ of the mother says sunshine can prevent vitamin D deficiency and the rest of the mothers or $31.8 \%$ of the respondents had poor knowledge regarding the effect of sunlight exposure, results on this study also lower than Turkey and this may be due to the reason of information and awareness creation about the effect of sunlight exposure (2). As shown from the entry $80 \%$ of the mothers knew the effect of sunlight exposure on the same wing the cross-sectional study conducted in Broun University on the effect of radiation revealed that $69,9 \%$ of the said that sunshine exposure had good effects like preventing rickets and vitamin $-\mathrm{D}$ deficiency (3). On this study the overall knowledge of the 
mothers about sunlight exposure was $61.14 \%$ but a study done in Sakarya, Turkey, to determine the extent of intentional sun exposure in infancy and the prevalence of maternal belief that potentially increases the children's harm risk from ultraviolet radiation showed that $79.7 \%$ of mothers named one benefit of intentional baby sunning, in this case, the result of in this study is lower than done in Sakarya, Turkey and the difference is due to health education of the community and information from mass media $(2,7)$. The cross-sectional study conducted in Debre Markos with regard to the assessment of KP of the mothers on sunlight exposure and its associated factors revealed that the overall knowledge score of the respondents were $60 \%$ but in this study the overall result of knowledge of mothers about sunlight exposure was $61.14 \%$, which is almost the same and in line with the study conducted in Debre Markos (15).

In this study from the total respondents $61 \%$ of mothers had positive attitude towards sunlight exposure and $39 \%$ had negative attitude towards sunlight exposure but the study conducted to assess behavioral intention and factors influencing intention of Ethiopian mothers to expose infants to sunshine revealed that $48.5 \%$ of the respondents had good attitude towards sunshine and the study also showed that $52.3 \%$ of them also said that sunshine has bad effect on health, in this regard on this study more study participants had positive attitude than the study conducted in Ethiopia but less than of mothers who were in bad attitude and the difference may be due to familial and environmental influences (10). In this study Age of the mothers $>35$ years -49 years were 1.96 time had bad attitude for sunlight exposure than age of mothers $<35$ years but the study conducted in Ethiopia revealed that showed that age $<=19$ years times, educational status and information1.633 trims significant predictors of poor attitude for sunlight exposure (10). The cross-sectional study conducted in Ghana, the results showed that $46.3 \%$ of them had positive attitude towards sunlight exposures and the majority of the respondents or $53.7 \%$ of the parents had poor attitude on the effect of sunlight exposure among their infants and from this study $61 \%$ and 39\% of mothers had good and negative attitude towards sunlight exposure (17).

From this study, the overall practice of mothers on the effect of sunlight exposure on their infants was 59.44\%. Regarding exposure of infants on sunlight exposure, 61.9\%(65) of mothers expose their infants on sunlight exposure but similar cross-sectional studies done in Sakarya on the assessment of sunlight exposure in infancy $87.5 \%$ of mothers exposed their infants on sunlight, in this case, this study revealed that lower number of study participants practice sunlight exposure than the study in Turkey, which difference may be due to socioeconomically 
and educational status of the individual (7). Another study conducted in Townsville, Australia reveal that $20 \%$ of mothers only warm their babies to sun lights due to the hot climatic environmental condition, $34.5 \%$ of the mothers do not expose their infants in sun in Australia in case of fear of skin cancer but in this study more of patents practice sunlight exposure than the study conducted in Australia and the difference may be due to climatic condition (12). A research is done in Jimma town on the assessment of rickets and the knowledge and practice of exposure to sunlight shows, $92.16 \%$ of mothers expose their children on sunlight daily but in this study d $61.5 \%$ of the mother expose their infants to sunlight exposure daily and the difference may be due to information and community awareness (11). The cross-sectional study conducted by Debre Markos with regard of the assessment of KP of the mothers on sunlight exposure and its associated factors revealed that practice of sunlight exposure was $93 \%$ of mothers exposed which was very higher when compared with this study(15). Generally mother's knowledge, practice and attitude were lower when compared with different kinds of literature.'

\section{Limitation}

The adequate sample size was not taken due to financial and time resource limitations.

* Financial and time resource was no enough to execute this research

* Lack of similar studies especially in Ethiopia made difficult in comparing results. Since the study is cross-sectional it does not show cause and effect between dependent and independent variables.

* The information was self-reported and no behavior of the mother was observed.

\section{Conclusion}

The overall knowledge, practice, and attitude of mothers about the effect of sunlight exposure were $61.14 \%, 59.44 \%$ and $61 \%$ respectively which was very lower when operand with the study conducted in the same is true for practice and attitude of mothers about sunlight exposure. Mothers gave different reasons for sunlight exposure like the sun can cause disease of cancers in newborns and infants. Another mother gave reasons like the environment is cold so, infants not get sunlight more than warming with closes but the fact is to prevent rickets not the purpose of warming. Generally, mothers practice is lower rates than knowledge and practice of mothers about sunlight exposure. 


\section{Recommendations}

Based on the results of this study the following recommendations are forwarded:

The policy makers, Ministry of health, Amhara regional health bureau, South Gondar zone health department and Woreda health office of Debre Tabor should create awareness about the benefit of sunlight exposure to the community.

Nongovernmental organizations should give involve to give training for mother to mother groups about the advantages of sunlight exposure.

Health professionals should provide appropriate information about the good effects of sunlight exposure at infancy.

Mass Media should create awareness about the health effect of sunlight exposure.

Finally, researchers should do further study to identify the knowledge, attitude, and practice of mothers with qualitative data about sunlight exposure

\section{Abbreviation and acronyms:}

AOR -Adjusted Odds Ratio, BSc-Bachelor of Science, CI-Confidence Interval, DTU -Debre Tabor University, ETB-Ethiopian Birr , HL-Hodgkin's Lymphoma, KAP -Knowledge, Attitude and Practice, LSA-Local Statistical Agency, MBA-Marriage by Abduction, MSc-Master of Science, OR-Odds Ratio, PI -Principal Investigator, SPSS-Statistical Package for Social Science, UVB-Ultra Violate B, UVR-Ultra Violate Rays

\section{Declarations}

Ethical approval and consent to participate: Ethical clearance was obtained from Research Ethics Committee of Debre Tabor university department of Nursing. Then, the participants of the study were informed about the purpose of the study, the importance of their participation, and their right to withdraw at any time. Verbal informed consent was obtained prior to data collection, written informed consent was obtained from a parent or guardian for participants under 16 years old. Then data collects from volunteer mothers. Mothers who are not practice Sunlight Exposure during the data collection period were advised regarding to use of Sunlight Exposure. 
Consent to publication: Not applicable

Availability of data and materials: Data will be available upon request from the corresponding author.

Competing interests: The authors declare that they have no competing interests.

Funding: This research didn't receive any grant from any funding agency in the public, commercial or not-for-profit sectors.

Authors' Contribution: DG, the corresponding author, worked on designing the study, training and supervising the data collectors, interpreting the result and preparing the manuscript. The coauthors namely EM, GM, played their role in analyzing and interpreting the result. Moreover, the co-authors wrote the manuscript. All authors were involved in reading and approving the final manuscript.

Acknowledgment: The author acknowledged data collectors, and supervisors. The authors are also deeply acknowledging Debre Tabour University and Debre Tabor. Last but not least, the respondents deserve sincere thanks for their kind responses.

\section{Reference}

1. Lauer BJ, Spector ND. Hyperbilirubinemia in the Newborn. Pediatr Rev. 2011;

2. Holick MF, Chen TC. Vitamin D deficiency: A worldwide problem with health consequences. Am J Clin Nutr. 2008;

3. Brash DE. Sunlight and the onset of skin cancer. Trends Genet 1997, 13: 410-414.

4.D.para Harrison SL, Buettner PG, MacLennan R. Why do mothers still sun their infants? J Paediatr Child Health.2015; 35: 296- 299.

5. A.Smar. Sunlight and the onset of skin cancer. Trends Genet 2014: 410-414

6. Holick MF. Deficiency of sunlight and vitamin D. BMJ 2015, 336: 1318-1319.

7. Cinar ND, Filiz TM, Topsever P, Ucar F, Akgul S, Gorpelioglu S. Intentional sun exposure in infancy in Sakarya, Turkey. Saudi Med J, 2006; 27 (8): 1222-5.

8. Holick M. Vitamin D deficiency. N Eng J Med 2013, 357, 266-81.

9. Glerup H, Mikkelsen K, Poulsen K, et al. Commonly recommended a daily intake of vitamin D is not sufficient if sunlight exposure is limited. J Intern Med 2000, 247, 260-8.

10. Sileshi L, Catherine D. Behavioral intention and factors influencing the intention of Ethiopian mothers to expose infants to sunshine. April 2015

11. Nihal A, Tuncay M, Pinar T, Suleyman G. Knowledge and behavior of parents concerning 
sunning their babies. BMC Pediatrics 2016, 6: 27

12. Harrison SL, Buettner PG, MacLennan R. Why do mothers still sun their infants? J Paediatr Child Health.2012; 35: 296- 299.

13. Lan H, Jolieke C, van der P, et al. Knowledge and Attitudes about Vitamin D and Impact on Sun Protection Practices among Urban Office Workers in Brisbane, Australia. July 2010.

14. Tefera B, Abebe G, Worku L. Micronutrient Deficiency. Jimma University, 2005

15. Abate A, Murugan R, Gualu T. Assessment of Practice and Factors Affecting Sunlight Exposure of Infants Among Mothers Attending Governmental Health Facilities in Debre Markos Town, East Gojjam, Ethiopia, 2015. Am J Nurs Sci [Internet]. 2016;5(1):30. Available from: http://www.sciencepublishinggroup.com/journal/paperinfo?journalid=152\&doi=10.11648/j.ajns. 20160501.15

16. Ahmed, M. C, Walder V et al. Knowledge and Attitudes of parents on the effect of sunlight and its associated factors on infants Cairo,2016

17.Ubud Alm. G.Mamur Assessment of parents on Knowledge, attitude, and practice of parents at the effect of sunlight exposure among their infants, Ghana, 2017 


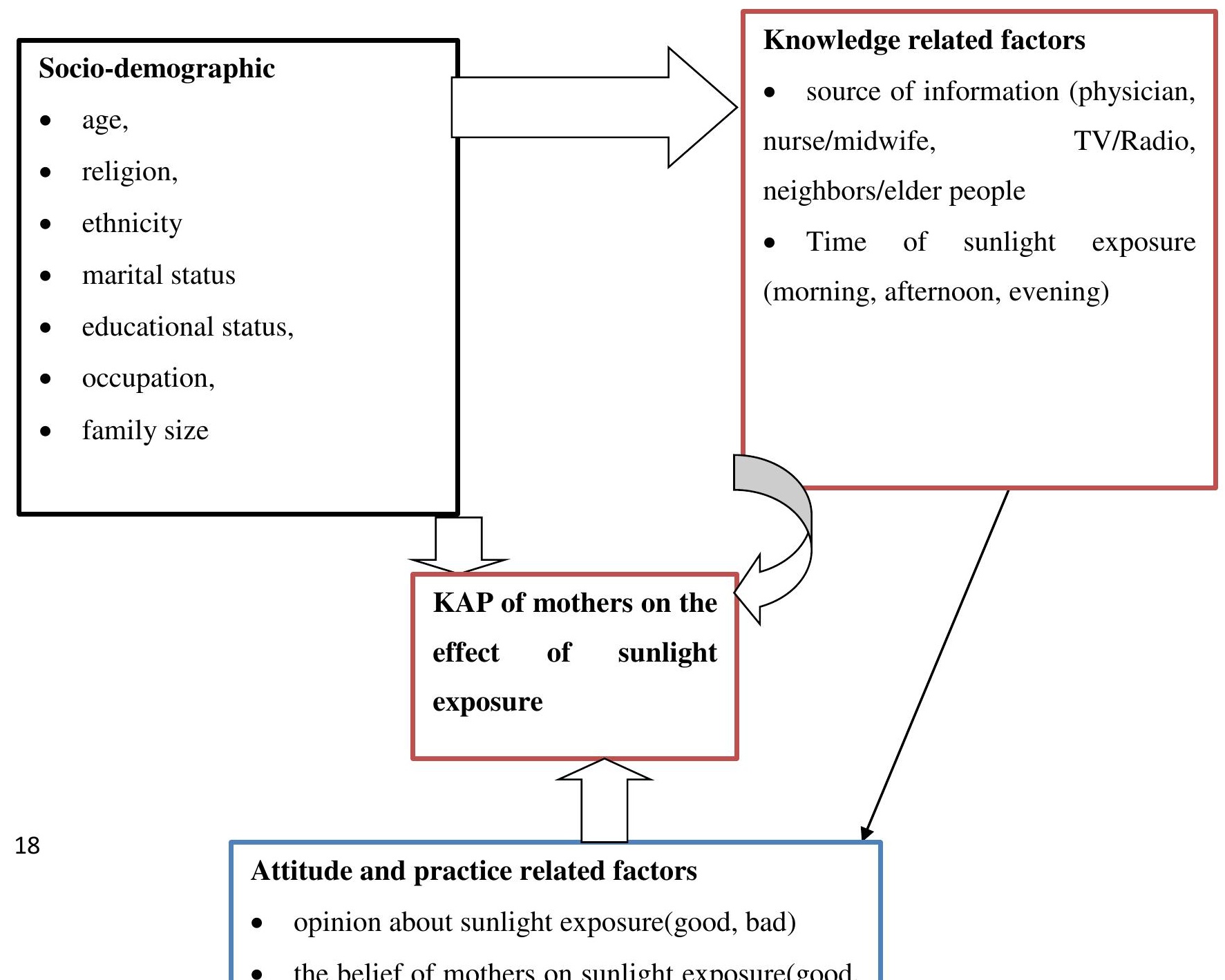




\section{Total sample size $(n)=105$}

Figure 2 sampling procedure of the study by stratification on the assessment of knowledge, attitude, and practice of mothers on the effects of sunlight exposure and its associated factors in Debre Tabor Town ,Northcentral,Ethiopia,2019.

Table 1 socio-demographic characteristics of the respondents on the assessment of the knowledge, attitude and practice of mothers on the effects of sunlight exposure and its associated factors among infants found in Debre Tabor Town, south Gondar administrative zone, Amhara regional state, north-central Ethiopia, 2019 ( $\mathrm{n}=105)$

Characteristics

\section{Age of the baby}

The mean age and STD of the baby

Age of the mother

The mean age of the mother

\section{Religion}

Orthodox

Muslim

protestant

Others(missionary

Ethnicity

Amhara

Others

\section{Marital status}

Frequency

$0.58 \pm 0.3$ years

$24.5 \pm 6.21$ years

$\mathrm{N}=105$

90

6

5

4.8

4

$\mathrm{N}=105$

101

4 
Single

Married

Divorced

Widowed

Occupation of the mother

Student

Housewife

Government employee

Private employee

Daily laborer

Merchant

The educational level of the mothers

Unable to read and write

Able to Read and write

Grade 1-6

Grade 7-10

Grade 11-12

Diploma and above

\section{Husbands educational status}

Unable to read and write

Able to Read and write

Grade 1-6

Grade 7-10

Grade 11-12

Diploma and above

\section{family size}

1-3

4-6

$>6$
$\mathrm{N}=105$

4

26

24.8

49

46.6

8

7.6

5

4.8

13

12.4

$\mathrm{N}=105$

14

18

17.1

6

5.7

7

6.7

13

12.4

47

44.8

$\mathrm{N}=105$

11

10.5

19

18.1

8

7.6

6

5.7

10

9.5

51

48.6

$\mathrm{N}=105$

79

75.2

18

17.2

8

7.6 
Table 2 Knowledge of mothers about sunlight exposure on the assessment of the knowledge, attitude and practice of mothers on the effects of sunlight exposure and its associated factors among infants found in Debre Tabor Town, south Gondar administrative zone, Amhara regional state, north-central Ethiopia, $2019(\mathrm{n}=105)$

Characteristics

Frequency

Percent $(\%)$

Do you know about the effect of sunlight exposure on your infants $\mathrm{N}=105$ Yes

No

If you answer yes for $\mathbf{Q} 201$ Source of information about sunlight $\quad \mathrm{N}=84$

Exposure

Physician

Midwife/nurse

10

12

Television/radio

7

8.3

Neighbors/elder people

Does sunlight exposure beneficial

$\mathrm{N}=105$

Yes

78

74.3

No 
If you answer yes for $\mathbf{Q} \mathbf{2 0 3}$ benefits of sunlight exposure $\mathrm{N}=78$

Strengthen bone

Strengthen teeth

5

6.4

Keep child warm

24

30.8

Produce vitamin D

9

11.5

Strengthen body

8

10.3

Does sunlight exposure harmful

$\mathrm{N}=105$

Yes

30

28.6

No

75

71.4

If you yes for Q No 205 harmful effect of sunlight?

$\mathrm{N}=30$

Skin cancer

16

Sterility

7

23.3

Blindness

7

Good time to expose infants on sunlight

$\mathrm{N}=105$

Morning

Afternoon

13

12.4

Evening

17

16.2

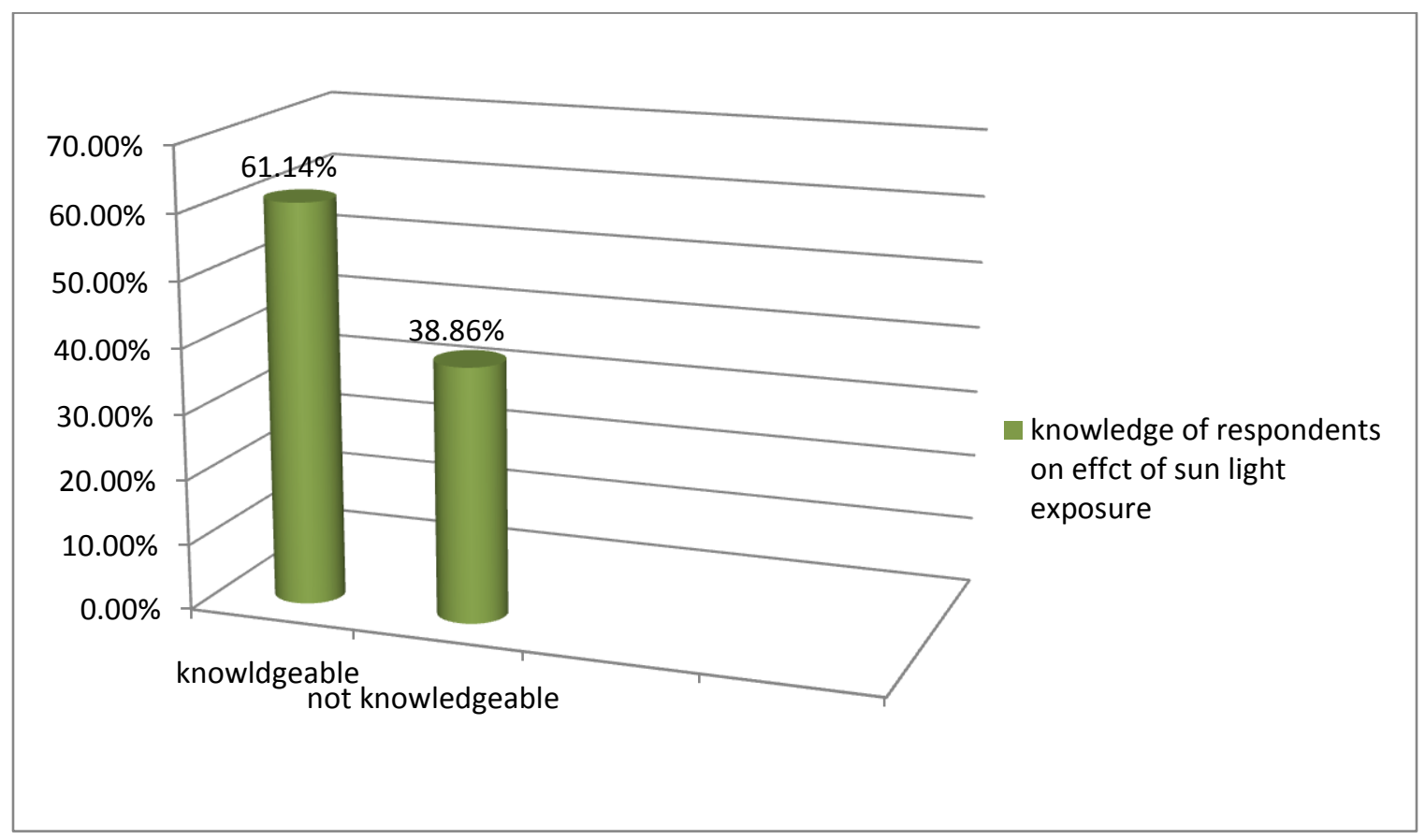


Figure 3 Knowledge of mothers about sunlight exposure on the assessment of the knowledge, attitude and practice of mothers on the effects of sunlight exposure and its associated factors among infants found in Debre Tabor Town, south Gondar administrative zone, Amhara regional state, north-central Ethiopia, $2019(\mathrm{n}=105)$

Table 3 Practice of mothers on sunlight exposure of their infants on the assessment of the knowledge, attitude and practice of mothers on the effects of sunlight exposure and its associated factors among infants found in Debre Tabor Town, south Gondar administrative zone, Amhara regional state, north-central Ethiopia, $2019(n=105)$

Characteristics

Do you expose your baby on sunlight?

Yes

No

Age infant start sunlight exposure

0-15 days

16-30 days

31-45 days

45 days and above

How frequently do you expose?

Daily

Sometimes

Where do you expose your baby on sunlight

Outdoor

Frequency

$\mathrm{N}=105$

65

40

$\mathrm{N}=65$

24

27

10

4

6.2

$\mathrm{N}=65$

40

15

$\mathrm{N}=65$

62

95.4

3
36.9

41.5

15.4

61.5

38,5

Percent (\%)

8.1

4.6

Indoor 
At what time of the day do you expose your baby $\quad \mathrm{N}=65$

Morning 8-10 AM 63

Mid-day 11AM-1 PM

Afternoon 2-4 PM

Condition of clothing during exposure

$\mathrm{N}=65$

Unclothed

30

46.1

With diapers and eye protection only

12

18.5

Partly covered

Completely covered

For how many minutes you expose your baby on $\mathrm{N}=65$

sunlight?

5-10 minute

10-15 minute

9

13.8

15-30 minute

7

10.8

Above 30 minute

Do you apply lubricants on your baby's body during

sunlight exposure?

69.2

Yes

No

If you apply, when do you apply?

$\mathrm{N}=45$

Before exposure

During exposure

6

13.3

After exposure

4

8.9

What things do you apply?

$\mathrm{N}=45$

Baby Vaseline

24

Baby lotion

18

40

Butter

6.7 


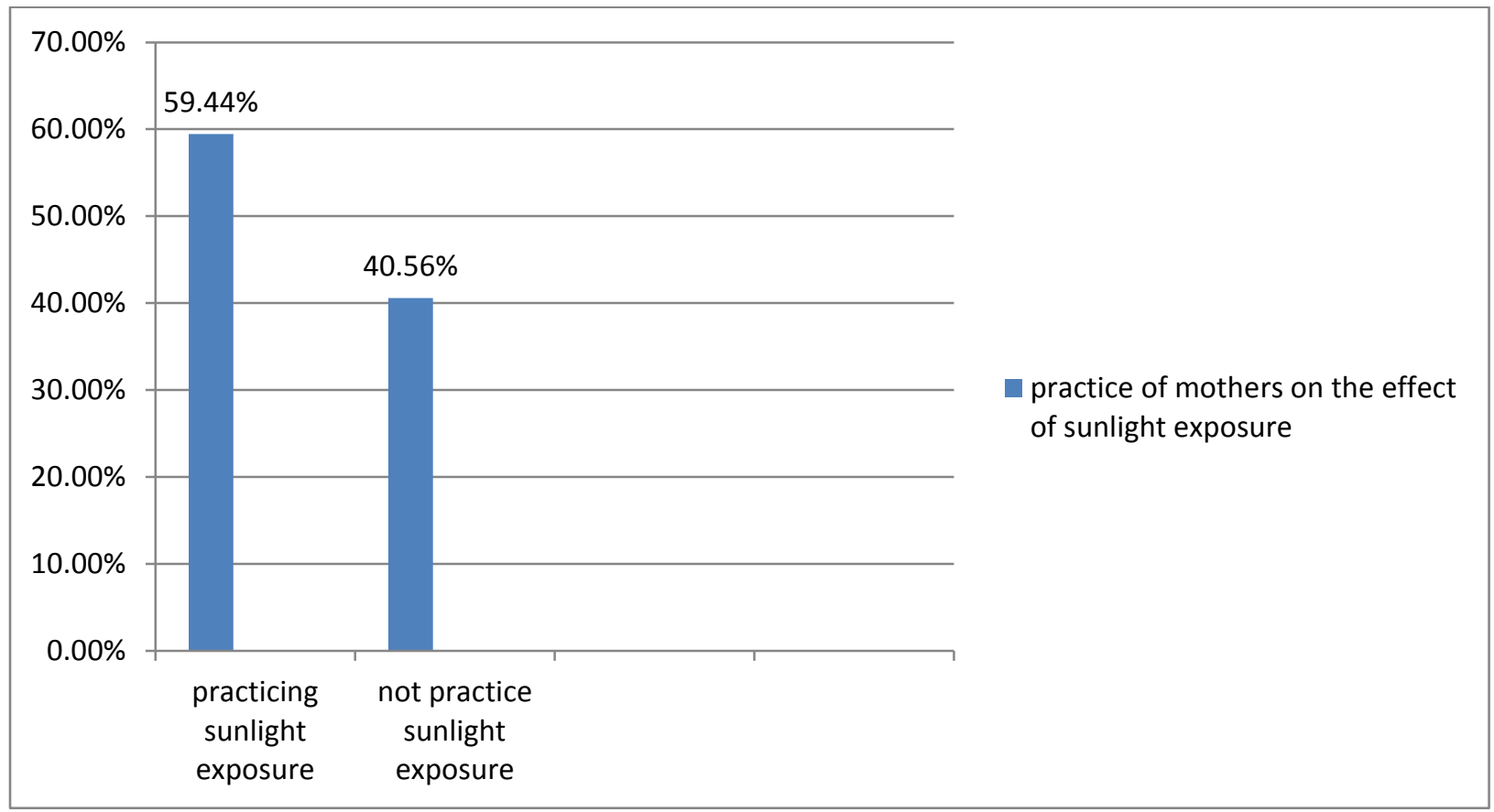

Figure 4 Practice of mothers on sunlight exposure of their infants on the assessment of the knowledge, attitude and practice of mothers on the effects of sunlight exposure and its associated factors among infants found in Debre Tabor Town, south Gondar administrative zone, Amhara regional state, north-central Ethiopia, $2019(\mathrm{n}=105)$ 
Table 4 Attitude of mothers about sunlight exposure infants on the assessment of the knowledge, attitude and practice of mothers on the effects of sunlight exposure and its associated factors among infants found in Debre Tabor Town, south Gondar administrative zone, Amhara regional state, north-central Ethiopia, $2019(\mathrm{n}=105)$

Characteristics

Do you have a positive attitude towards sunlight exposure Yes

No

if you say yes for $\mathrm{Q} 402$ what do you think about its impact can prevent rickets

skin Depigmentation

what is y our opinion about sunlight exposure

Good

Bad

Do you believe sunlight exposure to your infant bad effect Yes

No

Do you believe sunlight exposure has a good effect Yes

No

$\begin{array}{ll}\text { Frequency } & \text { Percent (\%) } \\ \mathrm{N}=105 & \\ 61 & 58.1 \\ 44 & 41.9 \\ \mathrm{~N}=61 & \\ 60 & 98.4 \\ 1 & 1.6 \\ \mathrm{~N}=105 & \\ 64 & 61 \\ 41 & 39 \\ \mathrm{~N}=105 & \\ 40 & 38.1 \\ 65 & 61.9 \\ \mathrm{~N}=105 & \\ 66 & 62.9 \\ 39 & 37.1\end{array}$




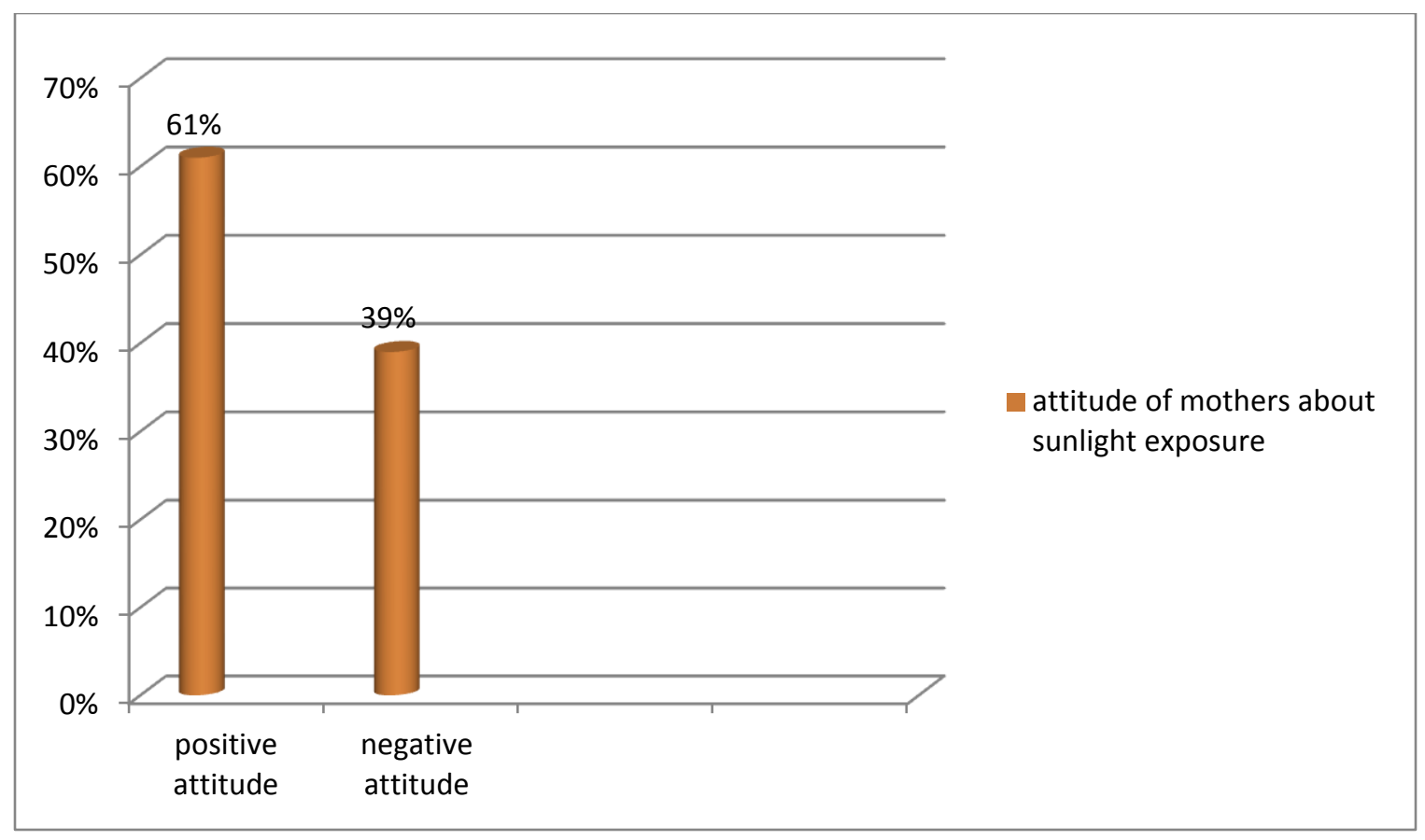

Figure 5 Attitude of mothers about sunlight exposure infants on the assessment of the knowledge, attitude and practice of mothers on the effects of sunlight exposure and its associated factors among infants found in Debre Tabor Town, south Gondar administrative zone, Amhara regional state, north-central Ethiopia, $2019(\mathrm{n}=105)$ 
Table 5: Factors associated with knowledge of mothers about sunlight exposure infants on the assessment of the knowledge, attitude and practice of mothers on the effects of sunlight exposure and its associated factors among infants found in Debre Tabor Town, south Gondar administrative zone, Amhara regional state, north-central Ethiopia, 2019 ( $n=105)$

Characteristics

Knowledge about sunlight exposure COR (95\%CI)

$\mathrm{AOR}(95 \% \mathrm{CI}$

Yes No

Age of the mother

$\mathrm{N}=105$

$<35$ years

20

25

1.76(1.34-6.74)

*1.4(1.2-5.89)

$>35$ years-49 years

44

16

1.00

1.00

Religion

$\mathrm{N}=105$

Orthodox

58

32

0.00

0.00

Muslim

2

4

1.95(1.2-3.76)

1.35(1.09-5.3)

protestant

2

3

0.00

0.00

Others(missionary

2

2

100

1.00

Ethnicity

$\mathrm{N}=105$

Amhara

61

40

100

1.00

Others

3

1

0.00

0.00

Marital status

$\mathrm{N}=105$

Single

2

10

$3.5(1.6-8.78)$

$* * 2.9(1.4-7.9)$

Married

48

28

0.00

0.00

Divorced

8

1

100

1.00

Widowed

6

2

0.00

0.00

Occupation of the mother $\quad \mathrm{N}=105$

Student

2

2

100

1.00

Housewife

6

20

1.8(0.97-4.8)

1.6(1.1-3.78)

Government employee

36

13

100

1.00

Private employee

6

Daily laborer

4

Merchant

10

2

0.00

0.00

1

100

1.00

3

0.00

0.00

The educational level of the $\mathrm{N}=105$

mothers 


\begin{tabular}{|c|c|c|c|c|}
\hline Unable to read and write & 4 & 10 & $1.76(1.08-6.45)$ & $* 1.5(1.00-7.2)$ \\
\hline Able to Read and write & 10 & 8 & 0.00 & 0.00 \\
\hline Grade 1-6 & 5 & 1 & 100 & 1.00 \\
\hline Grade $7-10$ & 5 & 2 & 0.00 & 0.00 \\
\hline Grade 11-12 & 10 & 3 & 0.00 & 0.00 \\
\hline Diploma and above & 30 & 17 & 100 & 1.00 \\
\hline Husbands educational status & $\mathrm{N}=105$ & & 0.00 & 0.00 \\
\hline Unable to read and write & 6 & 5 & 0.00 & 0.00 \\
\hline Able to Read and write & 12 & 7 & 100 & 1.00 \\
\hline Grade 1-6 & 5 & 3 & 0.00 & 0.00 \\
\hline Grade $7-10$ & 3 & 2 & 0.00 & 0.00 \\
\hline Grade 11-12 & 7 & 3 & 100 & 1.00 \\
\hline Diploma and above & 31 & 20 & 0.00 & 0.00 \\
\hline Family size & $\mathrm{N}=105$ & & 100 & 1.00 \\
\hline $1-3$ & 42 & 37 & 0.00 & 0.00 \\
\hline $4-6$ & 15 & 3 & 0.00 & 0.00 \\
\hline$>6$ & 7 & 1 & 100 & 1.00 \\
\hline $\begin{array}{l}\text { Good time to expose infants } \\
\text { on sunlight }\end{array}$ & $\mathrm{N}=105$ & & & \\
\hline Morning & 50 & 25 & 0.09 & 0.67 \\
\hline Afternoon & 2 & 11 & $3.6(0.67-5.8)$ & $* 3.2(1.02-6.4)$ \\
\hline Evening & 12 & 5 & 0.7 & 0.45 \\
\hline
\end{tabular}

NB:@=variables whose p-value $<0.2$ in Bivariate *significant at $\mathbf{p}<0.05$, ** significant at $\mathbf{p}<0.01$, $* * *$ significant at $\mathbf{p}<0.00$ 
Table 6: Factors associated with the practice of mothers about sunlight exposure infants on the assessment of the knowledge, attitude and practice of mothers on the effects of sunlight exposure and its associated factors among infants found in Debre Tabor Town, south Gondar administrative zone, Amhara regional state, north-central Ethiopia, 2019 ( $n=105)$

Characteristics

\begin{tabular}{|c|c|}
\hline & Yes \\
\hline Age of the mother & $\mathrm{N}=105$ \\
\hline$<35$ years & 26 \\
\hline$>35$ years -49 years & 39 \\
\hline Religion & $\mathrm{N}=105$ \\
\hline Orthodox & 56 \\
\hline Muslim & 2 \\
\hline Protestant & 3 \\
\hline Others(missionary & 3 \\
\hline Ethnicity & $\mathrm{N}=105$ \\
\hline Amhara & 62 \\
\hline Others & 3 \\
\hline Marital status & $\mathrm{N}=105$ \\
\hline Single & 4 \\
\hline Married & 56 \\
\hline Divorced & 2 \\
\hline Widowed & 3 \\
\hline Occupation of the mother & $\mathrm{N}=105$ \\
\hline Student & 2 \\
\hline Housewife & 20 \\
\hline Government employee & 24 \\
\hline Private employee & 6 \\
\hline Daily laborer & 3 \\
\hline Merchant & 10 \\
\hline The educational level of the & $\mathrm{N}=105$ \\
\hline
\end{tabular}

mothers

\section{Practice about sunlight exposure COR $(95 \% \mathrm{CI})$ No \\ $\mathrm{AOR}(95 \% \mathrm{CI}$}

$\begin{array}{lll}19 & 0.8 & 0.57 \\ 21 & 0.00 & 0.00\end{array}$

$34 \quad 0.00 \quad 0.00$

$\begin{array}{lll}3 & 0.06 & 0.00\end{array}$

$\begin{array}{lll}2 & 0.00 & 0.00\end{array}$

$\begin{array}{lll}1 & 1.00 & 1.00\end{array}$

$\begin{array}{lll}39 & 0.95 & 1.00\end{array}$

$\begin{array}{lll}1 & 0.00 & 0.00\end{array}$

$\begin{array}{lll}8 & 1.2(0.6-89) & 0.89\end{array}$

$\begin{array}{lll}20 & 0.00 \quad 0.00\end{array}$

$7 \quad 2.35(1.1-6.58) \quad * 1.87(1.00-768)$

$\begin{array}{lll}5 & 0.00 & 0.00\end{array}$

$1.00 \quad 1.00$

$0.06 \quad 0.00$

$25 \quad 1.18(1.67-5.2) \quad 1.00$

$20.00 \quad 0.00$

$2 \quad 3.9(0.7-5.6) \quad * 3.4(0.8-2.8)$

$30.00 \quad 0.00$ 


\begin{tabular}{|c|c|c|c|c|}
\hline Unable to read and write & 4 & 11 & $1.98(0.78-5.8)$ & $* 1.7(0.66-5.26)$ \\
\hline Able to Read and write & 12 & 6 & 0.00 & 0.00 \\
\hline Grade 1-6 & 5 & 1 & 100 & 1.00 \\
\hline Grade $7-10$ & 5 & 2 & 0.00 & 0.00 \\
\hline Grade $11-12$ & 10 & 3 & 0.00 & 0.00 \\
\hline Diploma and above & 30 & 17 & 100 & 1.00 \\
\hline Husbands educational status & $\mathrm{N}=105$ & & 0.00 & 0.00 \\
\hline Unable to read and write & 3 & 8 & $2.1(0.7-3.9)$ & $* 1.64(0.9-3.4)$ \\
\hline Able to Read and write & 10 & 9 & 100 & 1.00 \\
\hline Grade 1-6 & 6 & 2 & 0.00 & 0.00 \\
\hline Grade $7-10$ & 2 & 3 & 0.00 & 0.00 \\
\hline Grade $11-12$ & 8 & 2 & 0.02 & 0.00 \\
\hline Diploma and above & 33 & 18 & 0.07 & 0.03 \\
\hline Family size & $\mathrm{N}=105$ & & & \\
\hline $1-3$ & 45 & 34 & 0.00 & 0.00 \\
\hline $4-6$ & 14 & 4 & 0.00 & 0.00 \\
\hline$>6$ & 6 & 2 & 0.7 & 0.26 \\
\hline $\begin{array}{l}\text { How frequently do you } \\
\text { expose? }\end{array}$ & $\mathrm{N}=65$ & & & \\
\hline Daily & 33 & 7 & 0.02 & 0.00 \\
\hline Sometimes & 2 & 13 & $2.7(0.7-3.67)$ & $* 2.24(0.2-3.25)$ \\
\hline $\begin{array}{l}\text { Where do you expose your } \\
\text { baby on sunlight }\end{array}$ & $\mathrm{N}=65$ & & & \\
\hline Out door & 56 & 6 & 0.00 & 0.00 \\
\hline In door & 1 & 2 & $1.87(1.3-6.4)$ & $* 1.6(1.1-5.4)$ \\
\hline
\end{tabular}


Table 7: Factors associated with an attitude of mothers about sunlight exposure infants on the assessment of the knowledge, attitude and practice of mothers on the effects of sunlight exposure and its associated factors among infants found in Debre Tabor Town, south Gondar administrative zone, Amhara regional state, north-central Ethiopia, 2019 ( $n=105)$

Characteristics

\begin{tabular}{|c|c|c|c|c|}
\hline & Yes & No & & \\
\hline Age of the mother & $\mathrm{N}=105$ & & & \\
\hline$<35$ years & 30 & 15 & 0.00 & 0.00 \\
\hline$>35$ years -49 years & 13 & 39 & 2.8(1.09-8.79) & $* 1.96(1.3-7.6)$ \\
\hline Religion & $\mathrm{N}=105$ & & & \\
\hline Orthodox & 54 & 36 & 0.00 & 0.00 \\
\hline Muslim & 3 & 2 & 0.02 & 0.01 \\
\hline protestant & 3 & 2 & 1.00 & 1.00 \\
\hline Others(missionary & 3 & 1 & 1.00 & 1.00 \\
\hline Ethnicity & $\mathrm{N}=105$ & & & \\
\hline Amhara & 61 & 40 & 0.87 & 1.00 \\
\hline Others & 3 & 1 & 0.00 & 0.00 \\
\hline Marital status & $\mathrm{N}=105$ & & & \\
\hline Single & 2 & 10 & $1.9(1.23-7.9)$ & $* 1.43(1.3-8.1)$ \\
\hline Married & 54 & 22 & 0.00 & 0.00 \\
\hline Divorced & 4 & 5 & 1.00 & 1.00 \\
\hline Widowed & 4 & 4 & 1.00 & 1.00 \\
\hline Occupation of the mother & $\mathrm{N}=105$ & & & \\
\hline Student & 3 & 1 & 0.00 & 0.00 \\
\hline Housewife & 18 & 8 & 0.00 & 0.00 \\
\hline Government employee & 26 & 23 & 0.8 & 0.65 \\
\hline Private employee & 5 & 3 & 0.00 & 0.00 \\
\hline Daily laborer & 3 & 2 & 0.00 & 0.00 \\
\hline Merchant & 9 & 4 & 0.00 & 0.00 \\
\hline The educational level of the & $\mathrm{N}=105$ & & & \\
\hline
\end{tabular}
Attitude about sunlight exposure COR (95\%CI)
$\operatorname{AOR}(95 \% \mathrm{CI}$




\begin{tabular}{|c|c|c|c|c|}
\hline Unable to read and write & 3 & 12 & $2.4(0.8-7.6)$ & $* 1.97(1.00-8.6)$ \\
\hline Able to Read and write & 13 & 5 & 0.00 & 0.00 \\
\hline Grade 1-6 & 4 & 2 & 100 & 1.00 \\
\hline Grade $7-10$ & 6 & 1 & 0.00 & 0.00 \\
\hline Grade $11-12$ & 10 & 3 & 0.00 & 0.00 \\
\hline Diploma and above & 31 & 18 & 100 & 1.00 \\
\hline Husbands educational status & $\mathrm{N}=105$ & & 100 & 1.00 \\
\hline Unable to read and write & 4 & 7 & 0.00 & 0.00 \\
\hline Able to Read and write & 9 & 10 & 0.00 & 0.00 \\
\hline Grade 1-6 & 5 & 3 & 0.03 & 0.01 \\
\hline Grade $7-10$ & 2 & 3 & 0.08 & 0.05 \\
\hline Grade $11-12$ & 8 & 2 & 0.00 & 0.00 \\
\hline Diploma and above & 35 & 16 & 0.00 & 0.00 \\
\hline Family size & $\mathrm{N}=105$ & & & \\
\hline $1-3$ & 44 & 35 & 0.00 & 0.00 \\
\hline $4-6$ & 13 & 5 & 0.00 & 0.00 \\
\hline$>6$ & 1 & 1 & 0.2 & 0.1 \\
\hline $\begin{array}{l}\text { what is y our opinion about } \\
\text { sunlight exposure }\end{array}$ & $\mathrm{N}=105$ & & & \\
\hline Good & 50 & 14 & 0.01 & 0.01 \\
\hline $\mathrm{Bad}$ & 14 & 27 & $2.5(0.16-3.7)$ & $* 2.1(0.1-2.84)$ \\
\hline $\begin{array}{l}\text { Do you believe sunlight } \\
\text { exposure to your infant bad } \\
\text { effect }\end{array}$ & $\mathrm{N}=105$ & & & \\
\hline Yes & 38 & 2 & 0.00 & 0.00 \\
\hline No & 26 & 39 & $1.7(1.1-8.5)$ & $* 1.3(1.00-4.97)$ \\
\hline $\begin{array}{l}\text { Do you believe sunlight } \\
\text { exposure has a good effect }\end{array}$ & $\mathrm{N}=105$ & & & \\
\hline Yes & 56 & 10 & 0.00 & - \\
\hline No & 8 & 31 & $3.7(1.4-10.2)$ & $* * 3.3(1.5-8.9)$ \\
\hline
\end{tabular}


Figures

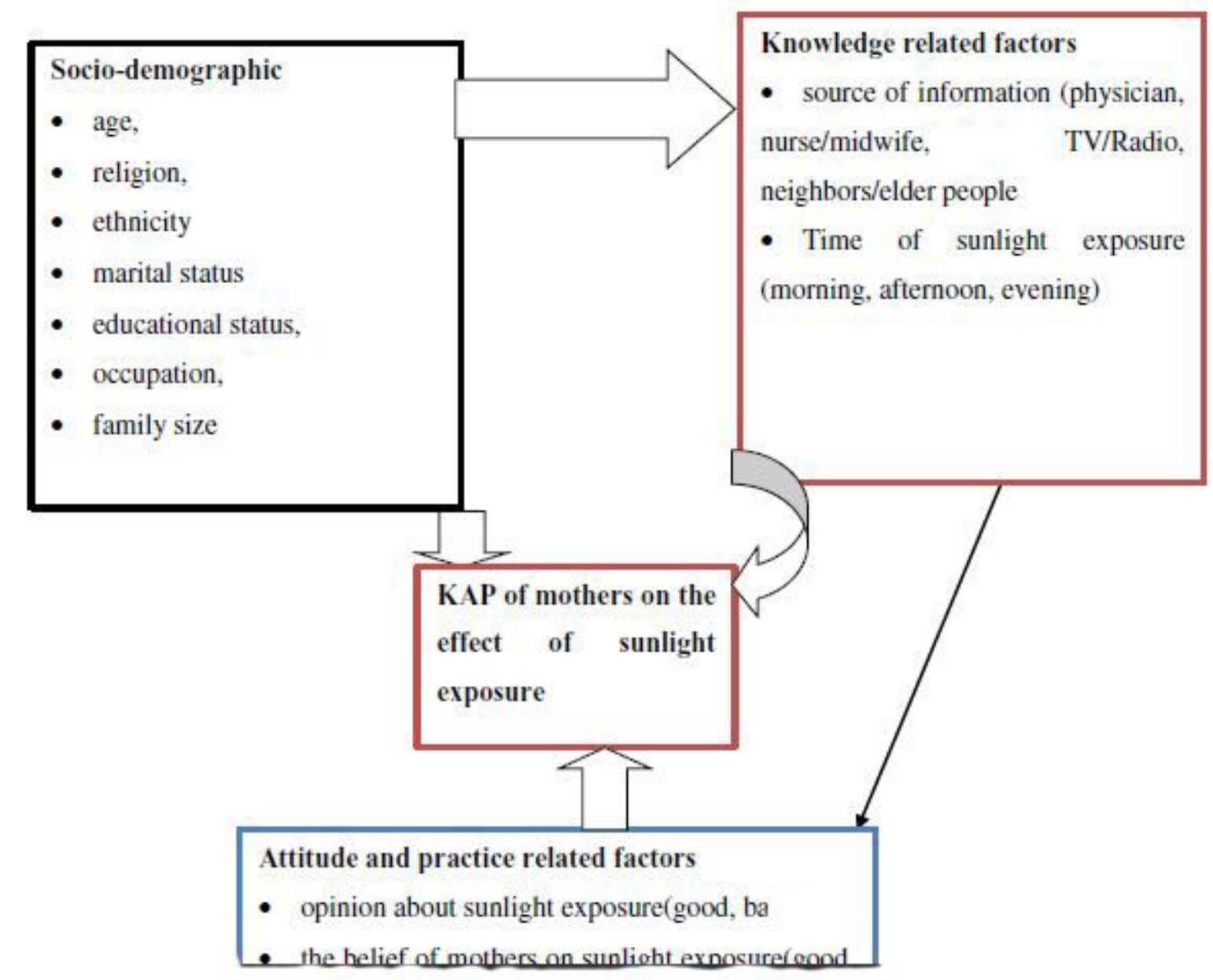

Figure 1

Conceptual framework for the study of knowledge, attitude and practice of mothers on the effects of sunlight exposure and its associated factors among infants found in Debre Tabor Town, South Gondar Zone, Amhara, Northcentral Ethiopia, 2019. 


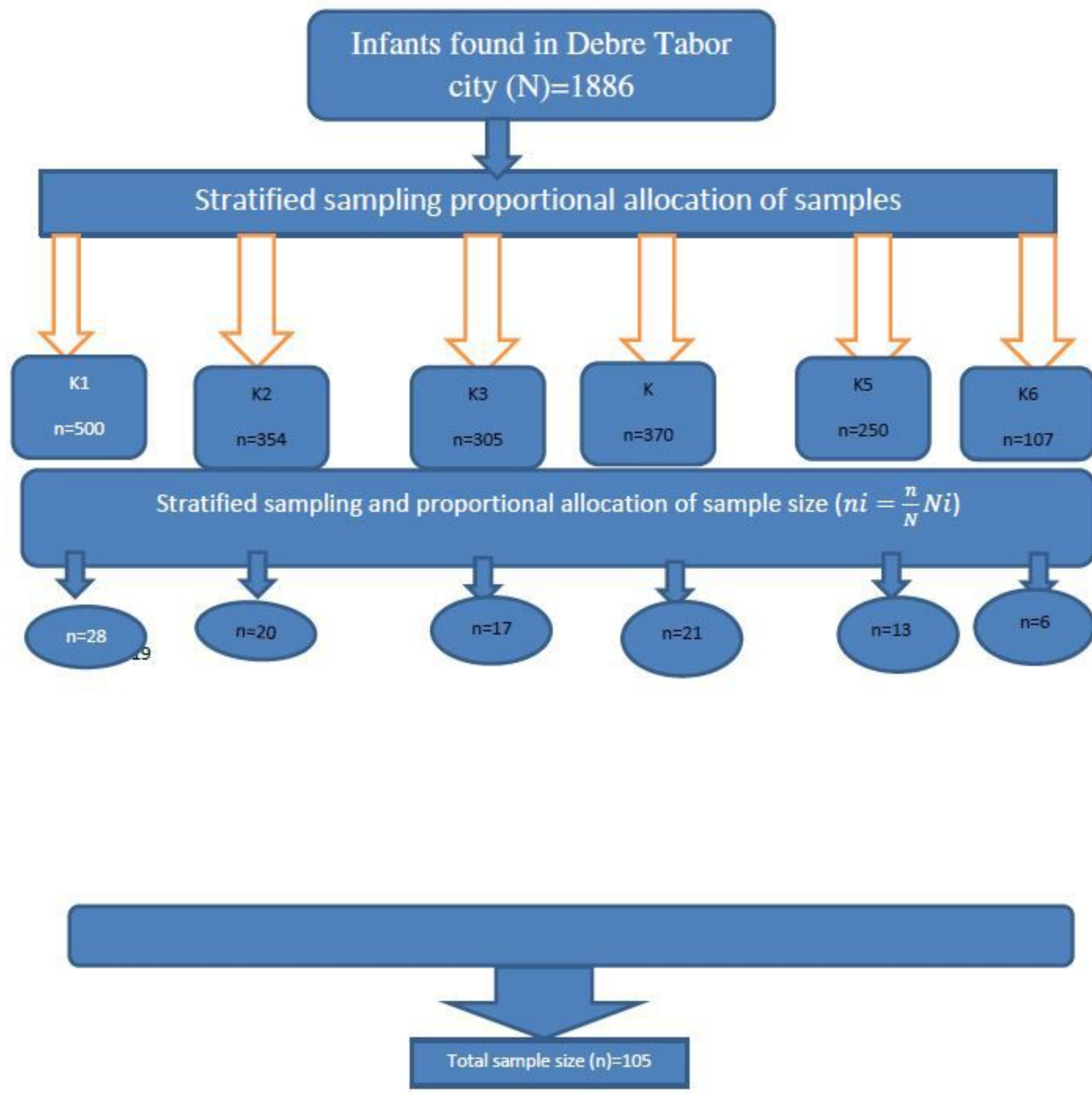

Figure 2

sampling procedure of the study by stratification on the assessment of knowledge, attitude, and practice of mothers on the effects of sunlight exposure and its associated factors in Debre Tabor Town, Northcentral,Ethiopia,2019. 


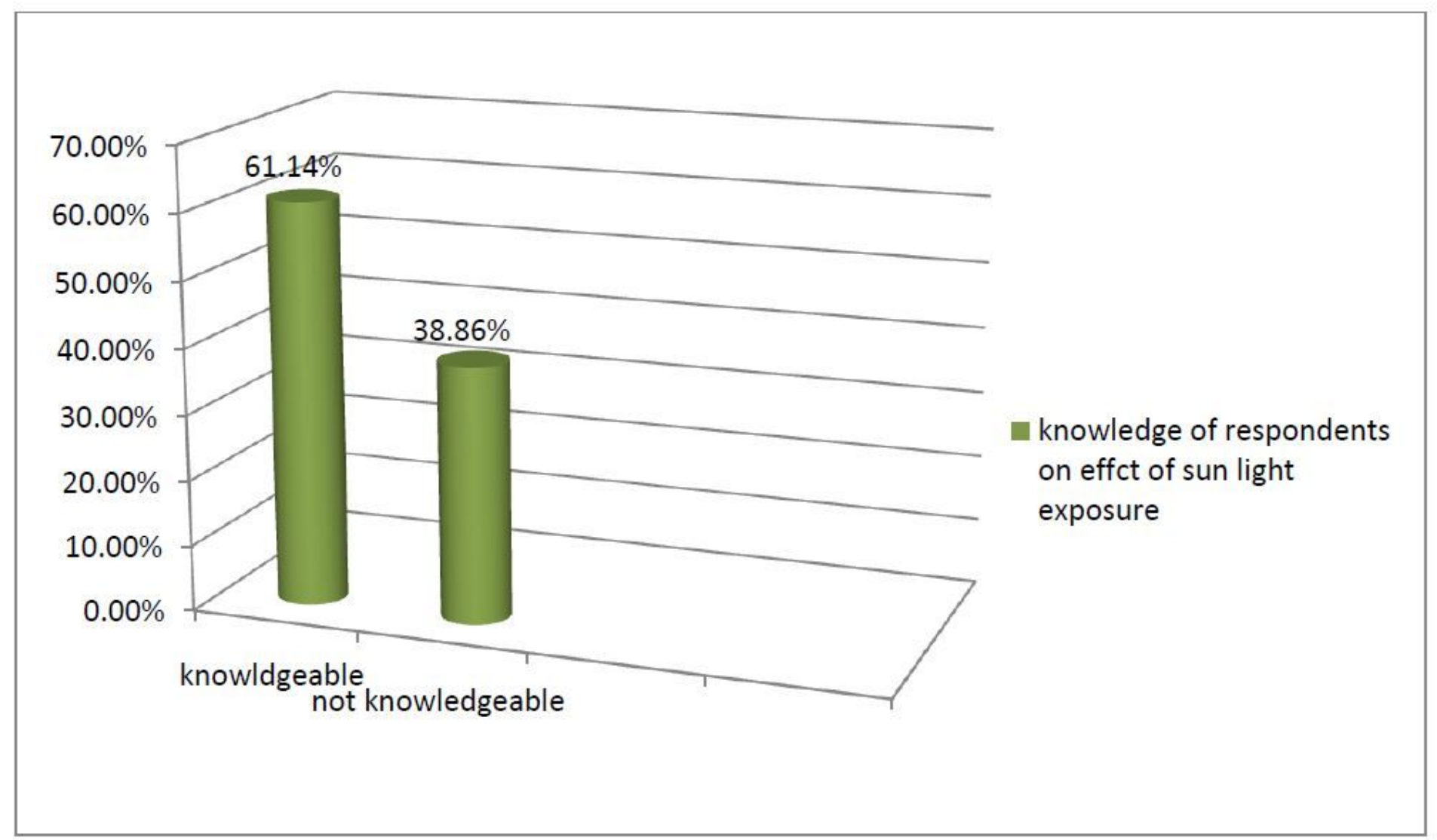

\section{Figure 3}

Knowledge of mothers about sunlight exposure on the assessment of the knowledge, attitude and practice of mothers on the effects of sunlight exposure and its associated factors among infants found in Debre Tabor Town, south Gondar administrative zone, Amhara regional state, north-central Ethiopia, $2019(n=105)$ 


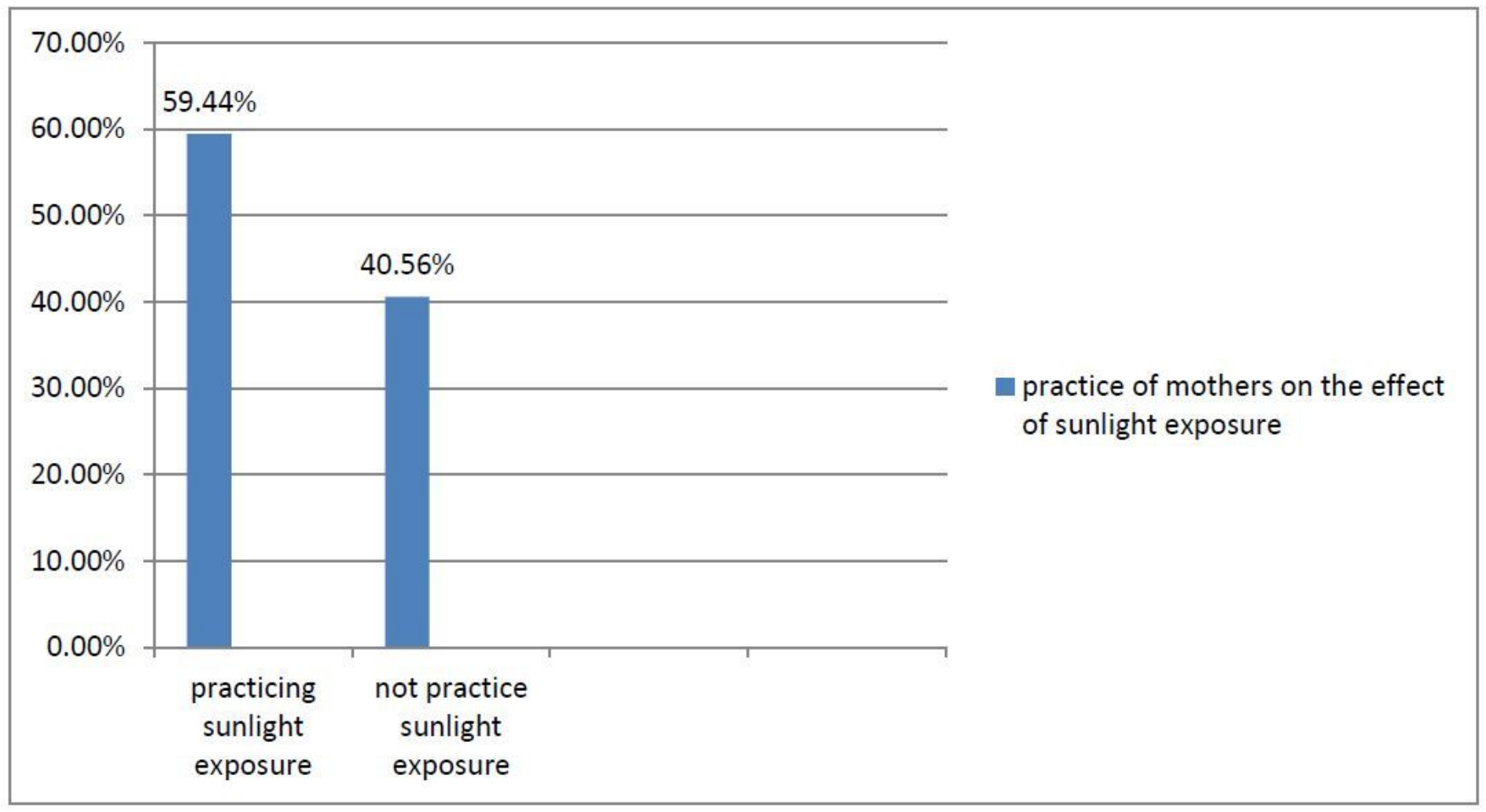

\section{Figure 4}

Practice of mothers on sunlight exposure of their infants on the assessment of the knowledge, attitude and practice of mothers on the effects of sunlight exposure and its associated factors among infants found in Debre Tabor Town, south Gondar administrative zone, Amhara regional state, north-central Ethiopia, $2019(n=105)$ 


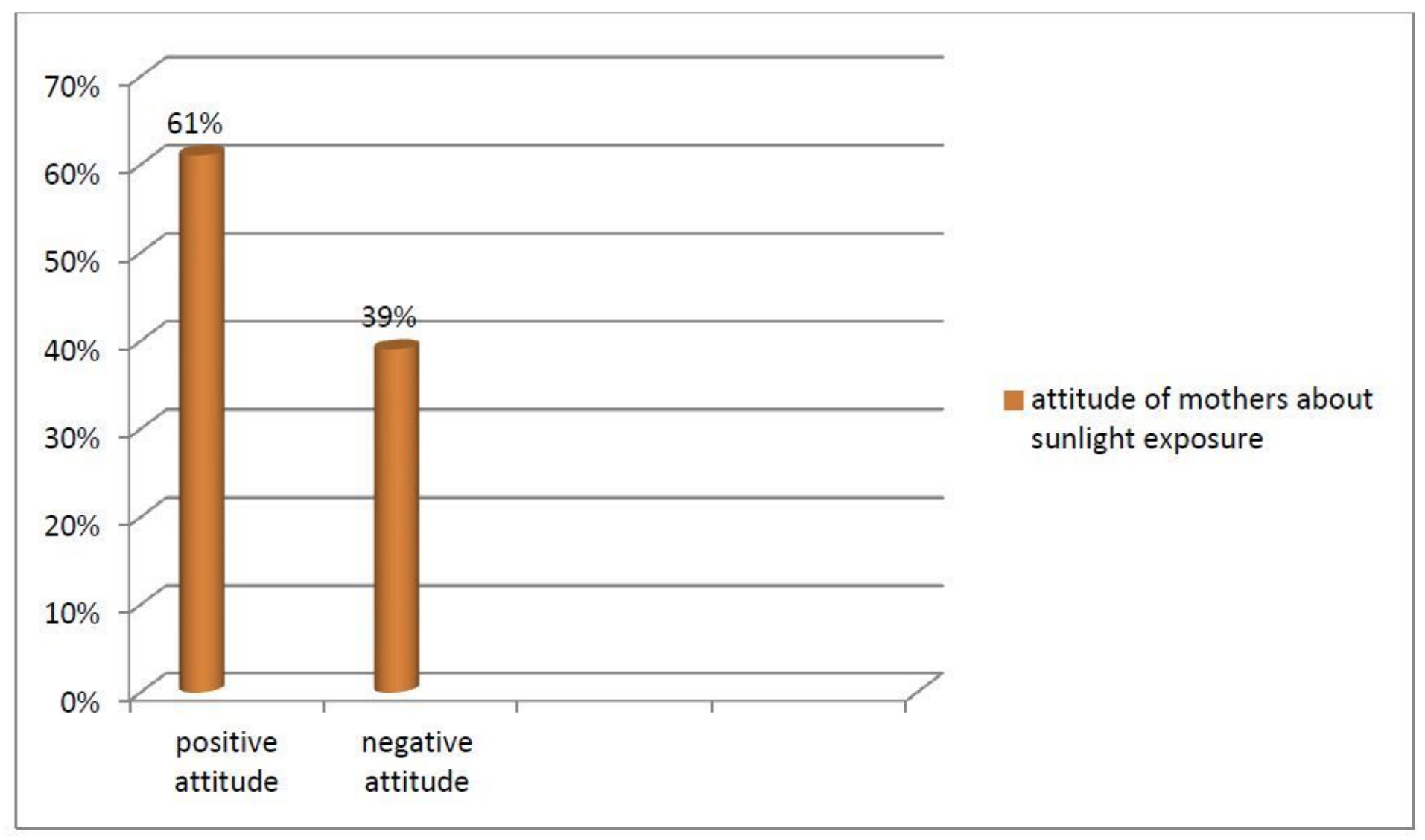

\section{Figure 5}

Attitude of mothers about sunlight exposure infants on the assessment of the knowledge, attitude and practice of mothers on the effects of sunlight exposure and its associated factors among infants found in Debre Tabor Town, south Gondar administrative zone, Amhara regional state, north-central Ethiopia, $2019(n=105)$ 